\title{
Erratum
}

\section{The ISO-SWS spectrum of planetary nebula NGC $7027^{\star}$}

\author{
J. Bernard-Salas ${ }^{1,2}$, S. R. Pottasch ${ }^{2}$, D. A. Beintema ${ }^{1}$, and P. R. Wesselius ${ }^{1}$ \\ 1 SRON Laboratory for Space Research, PO Box 800, 9700 AV Groningen, The Netherlands \\ 2 Kapteyn Astronomical Institute, PO Box 800, 9700 AV Groningen, The Netherlands \\ A\&A 367, 949-958 (2001), DOI:10.1051/0004-6361:20000435
}

Key words. ISM: abundances - planetary nebulae: individual: NGC 7027 - infrared: ISM: lines and bands - errata, addenda

In this paper we complemented the infrared spectrum with published ultraviolet and optical data to derive abundances. We found some mistakes in Table 3 which affect the ultraviolet fluxes. We present here the correct Table 3. These corrected ultraviolet fluxes imply the following changes: (1) The temperature of the O IV is now 14500 and better matches the trend (solid line) in Fig. 3 of the article. That of $\mathrm{Mg} \mathrm{V}$ is $13000 \mathrm{~K}$, slightly lower than the erroneous value. This last deviation does not alter any ionic abundance because at high ionization potentials only infrared lines (which are not temperature dependent) are used to derive the abundances. (2) The abundances of silicon, nitrogen and carbon should be $6.0(-6), 1.5(-4)$ and 5.2(-4) respectively and not $6.2(-6), 1.6(-4)$ and $6.0(-4)$ as published. Since the error on the abundances is $\sim 30 \%$, none of these erratum change any main conclusion of the paper. The authors regret these mistakes.

As minor details; in Fig. 1 (top-panel) there is a line at $4.48 \mu \mathrm{m}$ that has been labeled as H I but is [Mg IV]. In Table 2 the $3.625 \mu \mathrm{m}$ lines is identified as a blend of H I transitions, 6-20 and 6-19, but is probably due to Zn IV (see Dinerstein \& Geballe 2001).

\section{References}

Dinerstein, H. L., \& Geballe, T. R. 2001, ApJ, 562, 515

Send offprint requests to: J. Bernard-Salas,

e-mail: J .Bernard@sron.rug.nl

* Based on observations with ISO, an ESA project with instruments funded by ESA Member States (especially the PI countries: France, Germany, The Netherlands and UK) and with the participation of ISAS and NASA.
Table 3. Ultraviolet (IUE) and optical line fluxes (Keyes \& Aller 1990). Keyes fluxes were dereddened fluxes using an interstellar extinction of $E_{B-V}=0.85$.

\begin{tabular}{|c|c|c|c|}
\hline $\begin{array}{c}\text { Wavelength } \\
(\mathrm{nm})\end{array}$ & Ident. & $\begin{array}{c}\text { Measured } \\
\text { Fluxes }^{1}\end{array}$ & $\begin{array}{l}\text { Dereddened } \\
\text { Intensities }^{1}\end{array}$ \\
\hline 123.83 & $\mathrm{NV}$ & 0.12 & 240 \\
\hline 140.06 & O IV & 0.61 & 271 \\
\hline 148.50 & N IV] & 0.70 & 415 \\
\hline 154.83 & CIV & 20.80 & 12100 \\
\hline 157.57 & {$[\mathrm{Ne} \mathrm{V}]$} & 0.21 & 17.4 \\
\hline 164.20 & He II & 5.00 & 2700 \\
\hline 174.95 & N III] & 0.62 & 275 \\
\hline 189.20 & Si III] & 0.17 & 87.5 \\
\hline 190.67 & $\mathrm{C}$ III] & 4.23 & 2300 \\
\hline 190.88 & $\mathrm{C}$ III] & 6.85 & 3700 \\
\hline 232.55 & $\mathrm{C}_{\text {II }}$ & 0.61 & 526 \\
\hline 232.75 & C II & 0.48 & 411 \\
\hline 242.14 & {$[\mathrm{Ne}$ IV] } & 1.32 & 609 \\
\hline 242.45 & [Ne IV] & 0.43 & 198 \\
\hline 278.23 & {$[\mathrm{Mg} \mathrm{v}]$} & 0.83 & 98.4 \\
\hline 334.68 & {$[\mathrm{Ne} \mathrm{V}]$} & & 700 \\
\hline 342.68 & {$[\mathrm{Ne} \mathrm{V}]$} & & 2100 \\
\hline 372.62 & {$[\mathrm{O} \mathrm{II}]$} & 5.98 & 220 \\
\hline 372.88 & [O II $]$ & 2.19 & 80.2 \\
\hline 386.98 & [Ne III] & 43.34 & 1500 \\
\hline 396.86 & [Ne III] & 15.56 & 500 \\
\hline 436.44 & [O III] & 13.36 & 340 \\
\hline 447.10 & $\mathrm{He} \mathrm{I}$ & 1.90 & 45.4 \\
\hline 468.60 & He II & 32.3 & 660 \\
\hline 471.14 & [Ar IV] & 1.91 & 38.1 \\
\hline 474.00 & [Ar IV] & 6.74 & 131.7 \\
\hline 486.10 & $\mathrm{H}_{\beta}$ & 75.9 & 1360 \\
\hline 493.26 & [O III] & 0.17 & 2.9 \\
\hline 496.03 & [O III] & 388.61 & 6400 \\
\hline 500.82 & [O III] & 1178.73 & 19000 \\
\hline 551.70 & [Cl III] & 0.20 & 2.23 \\
\hline 553.80 & [Cl III] & 0.77 & 8.6 \\
\hline 658.40 & {$\left[\mathrm{~N}_{\mathrm{II}}\right]$} & 202.65 & 1500 \\
\hline 671.63 & [S II $]$ & 3.57 & 24.1 \\
\hline 673.10 & [S II $]$ & 8.20 & 56 \\
\hline 857.70 & [Cl II] & 1.01 & 3.6 \\
\hline
\end{tabular}

${ }^{1}$ Units: $10^{-12} \mathrm{erg} \mathrm{cm}^{-2} \mathrm{~s}^{-1}$. 